\title{
A configuração da carreira do magistério público do Estado do Pará a partir do Estatuto do Magistério
}

\author{
Rosana Maria Oliveira Gemaque ${ }^{1}$ \\ rgemaque@uol.com.br \\ Fabrício Aarão Freire de Carvalho \\ fafc33@gmail.com \\ Danielle Cristina de Brito Mendes ${ }^{3}$ \\ dany.britto@hotmail.com
}

\begin{abstract}
Resumo:
$\mathrm{O}$ artigo tem por objetivo apresentar os principais aspectos do Estatuto do Magistério Público Estadual do Pará (Lei n ${ }^{\circ}$ 5.351/1986), na perspectiva de compreender a carreira do magistério da rede pública do Estado do Pará. Para isso, analisam-se aspectos como: formas de ingresso, amplitude e movimentação na carreira. A partir da configuração da carreira, questiona-se se a mesma apresenta: atratividade, progressão e incentivos à formação. $\mathrm{O}$ texto está organizado de formar a abarcar aspectos que possibilitam discutir esses questionamentos, tais como: contexto histórico revelador da construção da carreira; questões de ordem conceituais sobre Estatuto e Plano de Carreira e Cargos e Remuneração; e análise do Estatuto em vigência. Conclui-se que, do ponto de vista legal, a carreira, configurada pelo Estatuto, Leis complementares e Portarias, assegura direitos aos profissionais do magistério público que os coloca em posição
\end{abstract}

1 Doutora em Educação pela Universidade de São Paulo, Brasil (2004). Professora da Universidade Federal do Pará.

2 Doutor em Educação pela Universidade de São Paulo, Brasil (2012). Professora da Universidade Federal do Pará.

3 Mestre em Educação pela Universidade Federal do Pará, Brasil (2012). Especialista em Educação da Secretaria de Educação do Pará. 
isonômica com outros funcionários públicos, como: férias, licenças; qualificação profissional; progressão; adicionais. Embora contenha elementos de estímulo à permanência do professor em sala de aula por meio de gratificações, na prática, a sua efetivação vem ocorrendo apenas parcialmente. Alguns aspectos não vêm sendo cumpridos pelos três últimos governos, como a progressão vertical e a hora atividade. A manutenção parcial dos direitos assegurados no Estatuto tem sido produto de lutas históricas da categoria.

Palavras-chave: Estatuto do Magistério do Pará - Valorização dos Professores - Carreira Docente

\section{1- Introdução:}

\subsection{Contexto histórico}

O Estatuto do Magistério Público do Estado do Pará, aprovado em 21/11/1986, resultou, sobretudo, da mobilização dos educadores do Pará. A organização dessa categoria se insere em um conjunto de mobilizações locais e nacionais que ocorreram desde o final da década de 1970, iniciadas pelas greves do ABC paulista e do movimento pelas Diretas Já.

Um marco na organização dos professores ocorreu, em 1979, com o evento "a marcha pela educação". Assim, conjuntamente com outros movimentos (pelo direito à moradia) encontrava-se o de luta pelo direito à educação, organizado por um grupo crítico de educadores.

Inicialmente, as "Lutas" dos educadores paraenses foram mobilizadas por questões salariais e de regulamentação da profissão.

Em 1979 surgiu a Associação dos Professores do Estado do Pará - APEPA coordenada por professores e militantes que organizavam comissões de bairros de Belém e associações em municípios do Estado.

A APEPA coordenou a primeira greve dos professores, em 1983, contra o então governador Jáder Barbalho (PMDB) e tinha como eixo o reajuste salarial da categoria. Por meio dessa greve foi conquistado o vencimento dos professores primários ao valor correspondente a um 
salário mínimo e a readmissão dos que haviam sido demitidos pela ditadura militar. Nesse período, a efetivação dos servidores do magistério ocorria por concurso público ou por decreto governamental.

Essa greve (1983) unificou os professores da rede estadual e da rede municipal de Belém que juntos lutavam pela construção da carreira e por melhores condições de trabalho no magistério. Essa unificação tem sido marcante na organização da categoria. Em Belém, a situação era um pouco mais diferenciada que a do Estado, devido ao fato de concurso público ser raro, o que demandava maior mobilização dos professores.

A partir dessa greve (1983), a APEPA transformou-se em Federação Paraense dos Professores do Estado do Pará - FEPEP, cujo primeiro presidente foi o Professor Edmilson Rodrigues que, após uma década, foi eleito Prefeito de Belém para o período de 1997-2000 e reeleito para 2001-2004.

Em 1985 ocorreu uma greve que contou com adesão de 95\% dos trabalhadores em educação, perdurando por 90 dias. Unificou professores, especialistas e servidores do Estado e do Município de Belém, sendo avaliada por representantes do Sindicado como a greve mais importante da categoria. A mesma ocorreu no governo de Jáder Barbalho e foi a mais reprimida. Um fato histórico ocorrido nessa greve foi o de 13 de junho de 1985 quando, em ato público, os grevistas ao mesmo tempo em que eram espancados pela polícia de choque cantavam o Hino Nacional. Com essa greve conquistaram: o direito à reformulação do Estatuto do Magistério do Estado (1957); o Piso Salarial; a gratificação ao magistério; a carreira com o interstício de 10 anos; e progressão a cada 2 anos, correspondente ao valor de 3,5\% de reajuste no salário; reajuste de quase $70 \%$ no salário; e pagamento de um salário mínimo para os funcionários de escola.

Em 1989, a Constituição do Estado do Pará foi promulgada e contou com a participação do então deputado estadual Edmilson Rodrigues (PT) que tratou, em especial, do capítulo relativo à Educação, sendo assegurado o direito: ao Regime Jurídico Único- RJU; ao Plano de Carreira; a constituição de Conselhos nas escolas; a eleições para provimento ao cargo de diretores a partir de listas tríplices. 
Em 1992, ocorreu a greve pela efetivação do RJU para todos trabalhadores da educação, aprovado em 1994. A Lei do RJU consolidou as conquistas da categoria como: o direito ao triênio em substituição ao qüinqüênio; a garantia das licenças; a efetivação da lei dos conselhos escolares; o direito a data-base, etc. Nesse período, o governo Carlos Santos (PMDB) garantiu o repasse ao salário dos profissionais da educação na conversão da moeda URV para o real. Isso possibilitou que não ocorressem perdas salariais.

Em 1995, inicia-se o governo de Almir Gabriel (PSDB- 1995-1998; 1999-2002) marcado pela a demissão de 13 mil temporários da rede de ensino, o que mobilizou uma nova greve da categoria. Esse governador descontou todos os dias parados e a única conquista possível foi à reintegração das professoras grávidas que haviam sido demitidas. A partir dessa greve houve um refluxo nas lutas e o SINTEPP conseguiu se reorganizar quatro anos depois, na greve de 1999, contra o Emendão de Almir Gabriel.

Em 1997, o então governador Almir Gabriel sumulou emendas à Constituição Estadual- CE-1989 que visavam extinguir o RJU no Estado. Diante disso, o SINTEPP acionou a Justiça e conseguiu ganhar a ação, mas, em julho de 1999, o governador fez aprovar as alterações na C.E. Em função disso, em agosto de 1999, os trabalhadores entraram em greve contra o que chamaram de "Emendão" que visava extinguir direitos como: o triênio que voltava a ser qüinqüênio; a diminuição de 80 para $50 \%$ da gratificação de nível superior; o aumento das horas de trabalho de 6 para 8 horas dos funcionários de escola; a contratação via emprego público, dentre outros. Mas o movimento saiu vitorioso da greve ao impedir a regulamentação das emendas.

Em 2003, Simão Jatene (PSDB-2003-2006) foi eleito governador do Estado, adotando a medida de congelamento salarial. Em função disso, em 2004, foi deflagrada uma greve, avaliada como difícil, pois não houve acordos entre o Sindicato e a categoria.

Em 2005, a então secretária de educação Rosa Cunha editou a Portaria de $N^{\circ}$ 009/2005 que levou à deflagração de nova greve, com mais adesões devido ao teor da mesma determinar retirada de direitos 
dos profissionais ao alterar a lotação. Em seguida editou a Portaria 010 que depois foi reformulada em 2007 pelo governo de Ana Júlia Carepa.

No governo de Ana Júlia Carepa (PT-2007-2010), a partir de 2007, houve a aprovação do Plano de Cargos Carreira e Remuneração do Magistério (PCCR). Contudo, o mesmo ainda precisará ser regulamentado para entrar em vigor.

\subsection{Estatuto e Plano de Carreira e Remuneração do Magistério - definições}

Uma importante medida de âmbito internacional que objetivou estimular a "valorização do profissional docente" dada à relevância de seu papel para a qualidade da educação, foi a aprovação do documento "Recomendação da OIT/UNESCO relativa ao Estatuto dos Professores", em Paris no dia 5 de Outubro de 1966.

As recomendações contidas nesse documento foram concebidas para servir de base para as leis nacionais e para as práticas dos professores. Fornecem um quadro internacional de referência para as suas discussões e negociações com professores e suas organizações em seus países. Nos seus 146 curtos parágrafos, divididos em 13 secções, essa Recomendação estabelece padrões internacionais para um leque vasto de questões que se relacionam com as mais importantes preocupações dos professores, em nível profissional, social, ético e material (UNESCO, 1966).

Em síntese, esse documento forneceu subsídios importantes para a definição de indicadores de "valorização docente" que deveriam orientar a elaboração das políticas para o setor, quais sejam: "preparação para a profissão docente e aperfeiçoamento dos professores" (formação inicial e continuada); "emprego e carreira profissional e direitos e deveres dos professores" (acesso e progressão na carreira); "condições favoráveis para um processo eficaz de ensino-aprendizagem" (condições de trabalho docente); e "remuneração dos professores" (vencimento-base e remuneração) (UNESCO, 1966).

Em âmbito nacional, conforme apontado pela legislação educacional aprovada nos últimos vinte anos de nossa história (Art. 206, inciso V da CF/1988; Lei 9.394/96; EC nº 14/96, Lei no 9.424/96; EC nº 53/2006; 
Lei 11.494/2007; Lei nº 11.738/2008; Resolução n ${ }^{0}$ 2/2009), a existência de uma Carreira bem remunerada e atrativa, com o estabelecimento de progressão e incentivo a qualificação e permanência do professor em sala de aula veio se configurando como um importante instrumento de valorização dos professores. Contudo, apesar de, no aspecto legal, a carreira ser contemplada como um indicadores da valorização docente, precisa ser melhor regulamentada e efetivada em âmbito nacional (ABREU, 2008; GATTI e BARRETO, 2009; BARBOSA, 2011).

No que concerne às leis que regulamentam a carreira docente, $\mathrm{o}$ levantamento sobre a estruturação da carreira docente tem revelado que a mesma vem sendo amparada legalmente em várias leis: Estatuto; Plano de Carreira e Remuneração; no Regime Jurídico Único; decretosleis; e portarias.

Em relação ao Estatuto e os Planos de carreira, observa-se que a linha divisória entre a definição de Estatuto e Plano de Carreira não é tão nítida. Entretanto Dutra Júnior et al (2000) arriscam-se a apresentar a seguinte diferenciação:

O Estatuto corresponde ao conjunto de normas que regulam a relação funcional dos servidores com a administração pública, dispondo, por exemplo, sobre investidura, exercício, direitos, vantagens, deveres e responsabilidades. O Plano de Carreira consiste no conjunto de normas que definem e regulam as condições e o processo de movimentação dos integrantes em uma determinada carreira, estabelecendo a progressão funcional e a correspondente evolução da remuneração (DUTRA JÚNIOR et al, 2000, p. 15,16).

De acordo com a definição apresentada pelos autores, o Estatuto seria uma lei mais geral e trataria, portanto, de questões mais amplas como investidura na carreira, deveres e responsabilidades do profissional, formas de exercício, dentre outros. O Plano de Carreira trataria de normatizações mais específicas acerca da carreira, tais como: progressão funcional e evolução da remuneração do profissional do magistério. Contudo, mesmo com estas especificações, há confusões relativas ao conteúdo de um e de outro. 
Dutra Júnior et al (2000) ao analisar um conjunto de leis estaduais em trabalho encomendado pelo Ministério da Educação (MEC) no âmbito do Projeto Nordeste/FUNDESCOLA, constatou que entre as vinte e uma leis estaduais consultadas (anteriores a 1996), quinze apresentavam matéria correspondente ao Plano de Carreira, embora intituladas como Estatuto do Magistério.

Conforme verificaremos, a seguir, o Estatuto do Magistério do Estado do Pará, regulamentado pela Lei $n^{0} 5.351 / 1986$, é bastante antigo e deixa de dispor, por exemplo, sobre elementos que lhe são peculiares (deveres e responsabilidades dos profissionais do magistério) e apresenta aspectos que deveriam aparecer apenas no Plano de Carreira ${ }^{4}$, como a movimentação do servidor mediante progressão vertical e horizontal.

\section{2- O Estatuto do Magistério do Pará em Análise}

A Lei Estadual no 5.351 de 21/11/1986, que trata do Estatuto do Magistério Público Estadual do Pará, regulamentada pelo Decreto n ${ }^{\circ} 4.714$ 09/02/1987, em consonância com as determinações da Lei de Diretrizes e Bases da Educação Nacional n ${ }^{\circ} 5.692 / 71$, estrutura a carreira e fornece outras orientações legais acerca "da atividade docente e especializada do ensino de $1^{\circ}$ e $2^{\circ}$ graus" da rede estadual do Pará (PARÁ, 1986, art. $1^{\circ}$ ).

Antes de centrarmos as análises acerca dos aspectos estruturantes da carreira, destacamos alguns conceitos relevantes para melhor compreensão e análise dos mesmos, quais sejam:

Pessoal do Magistério Público Estadual: é formado pelo conjunto de professores e especialistas de educação que ocupam cargos ou funções nas Unidades Escolares, e nos demais Órgãos do Sistema Estadual de Ensino, mantidos pelo Estado, que desempenha atividades docentes ou especializadas, com vistas a atingir os objetivos da Educação;

\footnotetext{
4 O Plano de Cargos, Carreira e Remuneração do Magistério do Estado do Pará (PCCR - Lei n 7.442) aprovado em 02 de julho de 2010, por sua vez, apresenta em seu texto legal aspectos que deveriam ter sido apresentados no Estatuto. Por exemplo, faz uma descrição sumária dos deveres e responsabilidades do Quadro Permanente do Magistério. Contudo, são leis complementares e as normas do Estatuto permanecerão aplicáveis aos profissionais do magistério, naquilo que não confrontar com o PCCR.
} 
Professor: é o membro do Magistério que exerce atividades docentes, oportunizando a educação do aluno;

Especialista de Educação: o membro do Magistério que, possuindo a respectiva habilitação, desempenha atividades de administração, planejamento, orientação, supervisão, inspeção, coordenação e/ ou pesquisa no campo da Educação (PARÁ, 1987, art. $1^{\circ}$, § único, incisos II e III).

Assim como estabelecido pela Lei 5.692/71, o Estatuto do Magistério não é destinado apenas ao professor - membro do magistério que exerce a docência - mas também ao especialista em educação - profissional da escola que exerce atividades relacionadas à gestão escolar e coordenação pedagógica. Essa categoria está contemplada pela conceituação estabelecida pelas Diretrizes Nacionais para elaboração dos Planos de Carreira ${ }^{5}$ no que concerne a "profissionais do magistério".

De acordo com o Estatuto, o cargo do pessoal do magistério púbico estadual é formado por dois quadros: (1) Quadro Permanente do Magistério Público Estadual - QPM e, (2) Quadro Suplementar do Magistério - QSM (PARÁ, 1986, art. 6º incisos I e II). O primeiro é composto por duas classes: atividade docente e especialista de educação - constituído por profissionais que possuem qualificação prevista em legislação federal e aprovados em concurso público. As suas subdivisões em cargos e níveis, bem como sua respectiva codificação e área de atuação, encontram-se sistematizados no quadro 1, em anexo.

Conforme evidenciado pelas informações contidas no quadro 1, a classe de Atividade Docente, composta pelo cargo de Professor, está classificada em quatro níveis de vencimento (AD-1; AD-2; AD-3; AD4), com base na formação: AD-1- Magistério de nível médio; AD-2 Magistério mais Estudos Adicionais; AD-3 - Licenciatura Curta; AD-4 - Ensino Superior.

5 São Considerados Profissionais do Magistério aqueles que desempenham as atividades de docência ou as de suporte pedagógico à docência, isto é, direção ou administração, planejamento, inspeção, supervisão, orientação e coordenação educacionais, exercidas no âmbito das unidades escolares de Educação Básica, com a formação mínima determinada pela legislação federal de Diretrizes e Bases da Educação Nacional (RESOLUÇÃO CNE/CEB No 2 de 05/2009, art. $2^{\circ}$, , $^{\circ}$ ). 


\section{Quadro 1}

Quadro Permanente do Magistério - QPM - do Estado do Pará.

\begin{tabular}{|c|c|c|c|c|c|}
\hline CLASSE & CARGO & NÍVEL & QUALIFICAÇÃO & CÓDIGO & $\begin{array}{c}\text { ÁREA DE } \\
\text { ATUAÇÃO }\end{array}$ \\
\hline \multirow{4}{*}{$\begin{array}{l}\text { Atividade } \\
\text { Docente }\end{array}$} & \multirow{4}{*}{ Professor } & AD-1 & $\begin{array}{c}\text { Habilitação de } \\
\text { Magistério de } \\
2^{\circ} \text { grau, obtida em } 03 \\
\text { séries. }\end{array}$ & $\begin{array}{c}\text { GEP- } \\
\text { MAD-401 }\end{array}$ & \multirow{2}{*}{$\begin{array}{c}\text { Ensino de } \\
1^{\circ} \text { grau de } \\
1^{\mathrm{a}} \text { a } 4^{\mathrm{a}} \text { séries } \\
\text { e educação } \\
\text { pré-escolar e } \\
\text { especial }\end{array}$} \\
\hline & & AD-2 & $\begin{array}{c}\text { Habilitação } \\
\text { específica de } \\
\text { magistério de } 2^{\circ} \text { grau } \\
\text { acrescida de estudos } \\
\text { adicionais }\end{array}$ & $\begin{array}{c}\text { GEP- } \\
\text { WWVD-401 }\end{array}$ & \\
\hline & & AD-3 & $\begin{array}{l}\text { Habilitação } \\
\text { específica em } \\
\text { Curso Superior de } \\
\text { Licenciatura de } \\
\text { curta duração }\end{array}$ & $\begin{array}{l}\text { GEP-M- } \\
\text { ACM01 }\end{array}$ & $\begin{array}{l}\text { Ensino de } 1^{\circ} \\
\text { grau de } 1^{\mathrm{a}} \text { a } 6^{\mathrm{a}} \\
\text { série e educação } \\
\text { pré-escolar e } \\
\text { especial }\end{array}$ \\
\hline & & AD-4 & $\begin{array}{l}\text { Habilitação específica } \\
\text { em curso de } \\
\text { licenciatura plena }\end{array}$ & $\begin{array}{l}\text { GEP-M- } \\
\text { ACM01 }\end{array}$ & $\begin{array}{l}\text { Todo o ensino } \\
\text { de } 1^{\circ} \text { e } 2^{\circ} \text { graus, } \\
\text { pré-escolar } \\
\text { e educação } \\
\text { especial }\end{array}$ \\
\hline \multirow{4}{*}{$\begin{array}{l}\text { Especialista } \\
\text { de educação }\end{array}$} & $\underset{\text { Escolar }}{\text { Administrador }}$ & \multirow{4}{*}{ EE-1 } & $\begin{array}{l}\text { Habilitação em } \\
\text { Cursos Superior de } \\
\text { Licenciatura curta } \\
\text { em Pedagogia - } \\
\text { Administração. }\end{array}$ & \multirow{4}{*}{$\begin{array}{c}\text { GEP- } \\
\text { MEE-402 }\end{array}$} & \multirow{4}{*}{$\begin{array}{c}\text { Unidade escolar } \\
\text { de } 1^{\circ} \text { grau } \\
\text { Unidades } \\
\text { previstas no } \S \\
\text { único do art. } 27\end{array}$} \\
\hline & $\begin{array}{l}\text { Supervisor } \\
\text { Escolar }\end{array}$ & & $\begin{array}{c}\text { Habilitação em } \\
\text { Curso Superior de } \\
\text { Licenciatura curta } \\
\text { em Pedagogia - } \\
\text { Supervisão escolar ou } \\
\text { portador de Registro } \\
\text { Definitivo. } \\
\end{array}$ & & \\
\hline & $\begin{array}{l}\text { Orientador } \\
\text { Escolar }\end{array}$ & & $\begin{array}{c}\text { Habilitação em } \\
\text { Curso Superior de } \\
\text { Licenciatura curta } \\
\text { em Pedagogia } \\
\text { - Orientação } \\
\text { Educacional ou } \\
\text { Portador de Registro } \\
\text { Definitivo }\end{array}$ & & \\
\hline & $\begin{array}{l}\text { Inspetor } \\
\text { Escolar }\end{array}$ & & $\begin{array}{c}\text { Habilitação em } \\
\text { Curso Superior de } \\
\text { Licenciatura curta em } \\
\text { Pedagogia - Inspeção } \\
\text { Escolar }\end{array}$ & & \\
\hline
\end{tabular}




\begin{tabular}{|c|c|c|c|c|c|}
\hline CLASSE & CARGO & NÍVEL & QUALIFICAÇÃO & CÓDIGO & $\begin{array}{c}\text { ÁREA DE } \\
\text { ATUAÇÃO }\end{array}$ \\
\hline \multirow{5}{*}{$\begin{array}{l}\text { Especialista } \\
\text { de educação }\end{array}$} & $\begin{array}{l}\text { Administrador } \\
\text { Escolar }\end{array}$ & \multirow{5}{*}{ EE-2 } & $\begin{array}{c}\text { Habilitação em } \\
\text { Curso Superior de } \\
\text { Licenciatura Plena } \\
\text { em Pedagogia - } \\
\text { Administração } \\
\text { Escolar }\end{array}$ & \multirow{5}{*}{ GEP-MEE-402 } & \multirow{5}{*}{$\begin{array}{c}\text { Unidade } \\
\text { escolar de } 1^{\circ} \\
\text { e } 2^{\circ} \text { graus } \\
\text { Unidades } \\
\text { previstas no } \\
\S \text { único do } \\
\text { art. } 27\end{array}$} \\
\hline & $\begin{array}{l}\text { Supervisor } \\
\text { Escolar }\end{array}$ & & $\begin{array}{l}\text { Habilitação em } \\
\text { Curso Superior de } \\
\text { Licenciatura Plena } \\
\text { em Pedagogia - } \\
\text { Supervisão Escolar } \\
\text { ou Portador de } \\
\text { Registro Definitivo }\end{array}$ & & \\
\hline & $\begin{array}{l}\text { Orientador } \\
\text { Escolar }\end{array}$ & & $\begin{array}{c}\text { Habilitação em } \\
\text { Curso Superior de } \\
\text { Licenciatura Plena } \\
\text { em Pedagogia } \\
\text { - Orientação } \\
\text { Educacional ou } \\
\text { Portador de Registro } \\
\text { Definitivo }\end{array}$ & & \\
\hline & $\begin{array}{l}\text { Inspetor } \\
\text { Escolar }\end{array}$ & & $\begin{array}{l}\text { Habilitação em } \\
\text { Curso Superior de } \\
\text { Licenciatura Plena } \\
\text { em Pedagogia - } \\
\text { Inspeção Escolar }\end{array}$ & & \\
\hline & $\begin{array}{l}\text { Planejador } \\
\text { Educacional }\end{array}$ & & $\begin{array}{l}\text { Habilitação em } \\
\text { Curso Superior } \\
\text { acrescido de } \\
\text { pós-graduação } \\
\text { em Planejamento } \\
\text { Educacional }\end{array}$ & & \\
\hline
\end{tabular}

Fonte: Anexo I da Lei No 5.351, de 21 de novembro de 1986.

A Classe de Especialista de Educação, composta pelos cargos de Administrador Escolar, Supervisor Escolar, Orientador Escolar, Inspetor Escolar e Planejador Educacional, está classificada em dois níveis de vencimento (EE-1 e EE-2). Ambas as classes têm determinada a sua classificação nos níveis de vencimento e sua área de atuação de acordo com a formação/qualificação: EE-1 - Licenciatura Curta em Pedagogia; EE-2 Licenciatura Plena em Pedagogia. Os profissionais de direção e coordenação escolar são classificados no Estatuto do Magistério (Art. 54) 
como profissionais de Administração Escolar pertencentes à classe de Especialistas de Educação. São profissionais responsáveis pelo exercício de funções do magistério relativas à "direção, planejamento, supervisão, inspeção, coordenação, orientação e pesquisa na área de ensino" (Art. $3^{\circ}$ ). Além dessas atividades poderão exercer coordenação de cursos, de área ou disciplina e assessoramento e a assistência em unidade escolar da Secretaria de Educação (Art. 54).

Aos profissionais de administração escolar é assegurada a mesma carreira dos professores, no que se refere: à paridade de remuneração (Art. $2^{\circ}$, Inciso II); ao progresso na carreira (Art. $2^{\circ}$, Inciso III); e à "valorização da qualificação, decorrente de cursos e estágios de formação, atualização, aperfeiçoamento ou especialização" (Art. 2 ${ }^{\circ}$, Inciso IV). Não há referências à forma de escolha dos especialistas em educação ou de professores para ocuparem cargos de administração escolar.

O segundo Quadro do Magistério é constituído pelo cargo em que os ocupantes não possuem a qualificação mínima exigida em Lei (QSM). A subdivisão em cargos, níveis e área de atuação, encontra-se sistematizada no quadro 2, em anexo.

\section{Quadro 2}

Quadro Suplementar do Magistério - QSM - do Estado do Pará.

\begin{tabular}{|c|c|c|c|}
\hline CARGO & NÍVEL & QUALIFICAÇÃO & ÁREA DE ATUAÇÃO \\
\hline \multirow{4}{*}{$\begin{array}{l}\text { Professor } \\
\text { Assistente }\end{array}$} & PA-A & $\begin{array}{l}4^{\mathrm{a}} \text { série do ensino de } 1^{\mathrm{o}} \\
\text { grau mais cursos intensivos } \\
\text { ou Exame de Capacitação }\end{array}$ & \multirow{2}{*}{$\begin{array}{l}\text { Ensino de } 1^{\circ} \text { grau } \\
\text { de } 1^{\mathrm{a}} \text { a } 4^{\mathrm{a}} \text { série }\end{array}$} \\
\hline & PA-B & $\begin{array}{c}8^{\mathrm{a}} \text { série do ensino de } 1^{\mathrm{o}} \\
\text { grau mais cursos intensivos } \\
\text { ou portadores de Diploma } \\
\text { de Agente de Ensino } \\
\text { primário }\end{array}$ & \\
\hline & PA-C & $\begin{array}{c}2^{\circ} \text { grau completo cursando } \\
\text { o } 3^{\circ} \text { grau }\end{array}$ & \multirow{2}{*}{$\begin{array}{l}\text { Ensino de } 1^{\circ} \text { grau de } \\
5^{\mathrm{a}} \text { a } 8^{\mathrm{a}} \text { série e em todo } \\
\text { o Ensino de } 2^{\mathrm{o}} \text { grau }\end{array}$} \\
\hline & PA-D & $\begin{array}{c}3^{\circ} \text { grau completo em área } \\
\text { não específica }\end{array}$ & \\
\hline
\end{tabular}

Fonte: Anexo II da Lei № 5.351, de 21 de novembro 
Conforme evidenciado no quadro 2, o cargo de Professor Assistente está classificado em quatro níveis de vencimento (PA-A; PA-B; PA-C e PA-D). Os profissionais ocupantes desse cargo têm determinada a sua classificação nos níveis de vencimento e área de atuação de acordo com a formação/qualificação apresentada: PA-A - $4^{\mathrm{a}}$ série do ensino de $1^{\mathrm{o}}$ grau mais cursos intensivos ou Exame de Capacitação; PA-B - $8^{\text {a }}$ série do ensino de $1^{\circ}$ grau mais cursos intensivos ou portadores de Diploma de Agente de Ensino primário; PA-C - $2^{\circ}$ grau completo cursando o $3^{\circ}$ grau; PA-D - $3^{\circ}$ grau completo em área não específica.

De acordo com o Estatuto, o ingresso do servidor no Quadro Suplementar só deveria ser permitido quando a oferta de professores, legalmente habilitados, não fosse suficiente para atender às necessidades de ensino (PARÁ, 1986, art. $7^{\circ}, 10 \S$ único) ${ }^{6}$. Contudo, não era bem isso o que vinha acorrendo. A título de ilustração: até janeiro de 2007, a quantidade de professores e de servidores temporários correspondia aproximadamente a dez mil e oitenta e oito (10.088), conforme revelado pelo coordenador de Descentralização da SEDUC/PA7 , em 2010.

Em função desse quantitativo de profissionais temporários (muitos deles contratados há mais de um ano), o governo do Estado foi acionado judicialmente pelo Ministério Público do Trabalho (MPT), obrigando-o a assinar o Termo de Ajustamento de Conduta (TAC), em 09/05/2005, que, entre outros dispositivos, estabelecia a realização de concursos públicos para a composição do quadro de pessoal da SEDUC ${ }^{8}$.

Chama atenção os arts.77 a 80 do Estatuto legitimaram o ingresso de professores leigos ${ }^{9}$ no sistema público de ensino do Estado do Pará,

6 A Constituição Federal de 1988 também faz referência a contratação de pessoal "por tempo determinado para atender a necessidade temporária de excepcional interesse público" (Art. 37, Inciso IX). Entretanto, não faz alusão a contratação de pessoal sem a formação mínima exigida em lei para atuação profissional.

7 Entrevista postada no site http://www.seduc.pa.gov.br/portal/ no dia 05/06/2009. Acessado em 06/06/2010.

8 O Estado atualmente utiliza como critério para a contratação de profissionais temporários em educação o que determina a Lei n 8.745 de 09 de dezembro de 1993, que dispõe sobre a contratação por tempo determinado para atender à necessidade temporária de excepcional interesse público. Segundo esta lei as contratações devem ser feitas por tempo determinado, obedecendo os prazos máximos de seis meses a um ano (Art. $4^{\circ}$, Incisos I e II) devendo esta relação de trabalho ser regida pela Consolidação das Leis de Trabalho (CLT) no período de vigência do contrato temporário.

9 É considerado professor leigo, àquele em exercício no magistério não habilitado para o nível de ensino em que atua. De acordo com a Lei 5.692/71, eram leigos os docentes que atuavam no ensino de $1^{\circ}$ grau, de $1^{\mathrm{a}}$ à $4^{\mathrm{a}}$ séries, sem habilitação específica de $2^{\circ}$ grau; que atuavam no ensino de $1^{\circ}$ grau, de $1^{\mathrm{a}}$ à $8^{\mathrm{a}}$ 
comprometendo o processo de valorização profissional e social do professor.

\section{1 - Forma de Admissão/Ingresso na Carreira}

Para ingresso na Carreira do Magistério Público Estadual e composição do quadro permanente, o Estatuto determina a realização de concurso público de provas ou de provas e títulos para a primeira investidura no cargo (PARÁ, 1986, art. 12). Contudo, o termo "para primeira investidura no cargo" aliado aos artigos da seção IV que tratam da "ascensão" se apresenta como um diferencial dentre os critérios de ingresso na carreira, tendo em vista que é permitido ao servidor mudar de classe, de cargo e de categoria funcional por meio da ascensão, como pode ser observado no art.19:

A Ascensão Funcional a cargos do Quadro Permanente do Grupo Magistério é permitida: I - A ocupantes de cargos do Grupo Magistério de uma para outra classe; II - Aos Especialistas de Educação de um para outro cargo dentro da mesma classe; III Aos ocupantes de categorias funcionais integrantes de outros grupos ocupacionais do Governo do Estado do Pará (PARÁ, 1986, art. 19).

Mediante a isso era permitido ao integrante do Quadro Permanente do Magistério, concursado para a "Classe Docente", ingressar (mudar) para a "Classe de Especialista” e vice-versa; ao funcionário pertencente a "Classe de Especialista", concursado para o cargo de Administrador Escolar, por exemplo, ingressar (mudar) em outro cargo (Supervisor Escolar, Orientador Escolar, Inspetor Escolar e Planejador Educacional) dentro da mesma classe. O mais grave nisso tudo, por meio da ascensão funcional, era permitido aos integrantes de outros grupos ocupacionais do Governo do Estado do Pará, o ingresso no Quadro Permanente do Magistério.

Esses dispositivos revelam certa flexibilidade no ingresso ao magistério, uma vez que era permitido ao profissional concursado em

séries, sem habilitação específica de grau superior, ao nível de graduação, representada por licenciatura de $1^{\circ}$ grau obtida em curso de curta duração; e que atuavam em todo o ensino de $1^{\circ}$ e $2^{\circ}$ graus, sem a habilitação específica obtida em curso superior de graduação correspondente a licenciatura plena. 
outra área, mediante processo seletivo interno (restritito a poucos) e realização de treinamento, ocupar outra vaga no serviço público na área de educação. Ressalta-se que o Estatuto foi aprovado antes da Constituição Federal.

Segundo Dutra Júnior et al (2000), até a promulgação da CF/1988 (art. 37, inciso II - que passou a exigir concurso público para investidura em cargo ou emprego público), a ascensão serviu como "mecanismo de burla ao princípio do concurso público", pois qualquer servidor poderia mudar para um cargo de vencimento superior ao que percebia, mediante alguns critérios mínimos ou realização de concurso interno (2000, p. 91).

A partir da CF/1988, segundo os autores:

Foram vedadas as formas de provimento derivado, como ascensão (ou acesso), a transferência (reenquadramento em cargo distinto, com mudança de atribuições) e o aproveitamento (mudança para outra carreira, sem o concurso público), que são formas de ingresso em carreira diversa daquela para a qual o servidor público ingressou por concurso (DUTRA JÚNIOR et al, 2000, p. 91).

\section{2- Formas de Progressão/Evolução na Carreira}

De acordo com o Decreto ${ }^{\circ}$ 4.714/1987 que regulamenta o Estatuto, a progressão na carreira pode acontecer de forma:

I - Horizontal, considerando tempo de serviço em funções de Magistério e assiduidade;

II - Vertical, em consequência da apresentação, pelo funcionário, de uma nova habilitação (PARÁ, 1987, art. $3^{\circ}$, incisos I e II).

A primeira trata da elevação do funcionário a referência imediatamente superior a que pertence, dentro do mesmo nível, considerando o tempo de efetivo exercício em função do magistério e a assiduidade mediante a apuração da frequência (PARÁ, 1987, art. $4^{\circ}, \S 6^{\circ}$ ).

Tratando-se especificamente do QPM, o Estatuto estabelece para cada nível de vencimento (AD-1; AD-2; AD-3; AD-4 e EE-1 e EE-2), dez referências (REF. 1; REF. 2; REF. 3; REF. 4; REF. 5; REF. 6; REF. 7; REF. 8; REF. 9; REF. 10). O servidor progride horizontalmente a cada dois anos, 
tendo acréscimo salarial de 3,5\%, calculados sobre o seu vencimento-base (PARÁ, 1986, art. $8^{\circ}$ ). Caso o servidor do QPM permanecesse no mesmo nível, levaria um período de vinte anos para chegar à última referência da carreira e permaneceria de cinco (no caso das mulheres) a dez anos (no caso dos homens) com a progressão estagnada e sem acréscimo salarial, até atingir vinte e cinco anos de efetivo exercício do magistério.

Para o servidor progredir verticalmente na carreira, "de um para outro cargo dentro da mesma classe" ${ }^{10}$, deveria apresentar a Secretaria de Estado de Administração (SEAD) documentação comprobatória da escolaridade exigida para o cargo pretendido (PARÁ, 1987, art. 5).

Apesar da garantia legal do direito à progressão vertical, por titulação, desde 1995, esse dispositivo não vem sendo cumprido, por decisão do governo do Estado, por entendê-la incompatível com os preceitos constitucionais (arts. $37^{\circ}, \mathrm{XIV}$ e $7^{\circ}, \mathrm{IV}$ ), visto que o inciso II, art.18, estabelece que a progressão vertical consiste na "elevação do professor GEP-M-AD-401 de um para outro cargo dentro da mesma classe". No entendimento do governo, esse tipo de progressão constitui ascensão funcional (passagem de um cargo para outro), o que é proibido pela Lei Maior. Assim, define que a aplicabilidade futura da progressão funcional dependeria de alterações legais no Estatuto. Por outro lado, a assessoria jurídica do SINTEPP, com base no parecer da OAB/PA e $\mathrm{OAB} / \mathrm{AP}$, entendia que não há passagem de um cargo para outro, e sim a elevação de nível dentro do mesmo cargo (professor). Durante muito tempo, essa ação foi questionada judicialmente e paralelamente havia um indicativo de reformulação do Estatuto, que foi protelada pelos dirigentes da SEDUC. Essa situação levou alguns professores, com formação em nível superior, a tomarem a seguinte medida: solicitar exoneração do quadro permanente para serem contratados ou se submeteram a um novo concurso público. No novo contrato, passavam a receber como a AD4 (temporários ou concursados) e iniciavam a carreira novamente.

\footnotetext{
10 Art. 18, inciso II define a progressão Vertical como "elevação do Professor GEP-M-AD-401 de um para o outro cargo, dentro da mesma classe" (PARÁ, 1986). Contudo, de acordo com a Assessoria Jurídica do SINTEPP (Sindicato dos Trabalhadores em Educação Pública do Pará), com base no parecer da $\mathrm{OAB} / \mathrm{PA}$, entende que não há passagem de um cargo para outro, e sim a elevação de um nível para outro dentro do mesmo cargo (GEMAQUE, 2004, p. 167).
} 


\section{3- Vencimento e Remuneração do Magistério Público Estadual}

Segundo Noronha (2009) "remuneração" é o termo mais apropriado para definir o pagamento total do servidor público ou aquele assemelhado que mantém com a administração pública relação estatutária de trabalho, como é o caso do pessoal do magistério público estadual.

Na Lei Federal no 8.112/1990 e na Lei Estadual nº 5.810 (PARÁ, 1994, art. 116) o termo utilizado é vencimento, entendido como a retribuição pecuniária devida ao servidor pelo exercício de cargo público com valor padrão fixado em Lei. Este valor acrescido das vantagens pessoais de caráter permanente, gratificações, adicionais, bonificações, corresponde à remuneração total auferida ao servidor (PARÁ, 1994, art. 118; DUTRA JÚNIOR, 2000; NORONHA, 2009).

O vencimento do Quadro Permanente do Magistério e do Quadro Suplementar depende da jornada de trabalho e é proporcional a respectiva referência e nível em que o professor estiver enquadrado (PARÁ, 1986, art. $29, \S \S 1^{\circ}$ e $2^{\circ}$ ). Além do vencimento-base, a remuneração total do servidor do magistério poderá ser composta pelas seguintes vantagens:

I - Salário-família; II - Gratificações: a) de titulares; b) de magistério; c) de adicional por tempo de serviço; d) pró-labore; e) pelo exercício de função; III - Diárias; IV - Ajuda de Custo; V - Outras previstas em lei (PARÁ, 1986, art. 30, incisos I a V).

O professor em regência de classe perceberá a gratificação de magistério, fixada em 10\% (dez por cento) do respectivo vencimento base. Quando em regência de classe ou em ensino itinerante de educação especial, fará jus à gratificação no percentual de 20\% (vinte por cento) sobre o valor do vencimento base (PARÁ, 1986, art. 35, § único).

A gratificação adicional por tempo de serviço corresponde a 5\% (cinco por cento) do vencimento ou remuneração e ocorrerá por qüinqüênio. Além disso, ao servidor que completar 25 anos de efetivo exercício no Magistério será concedida também a gratificação correspondente a 10\% (dez por cento) do respectivo vencimento ou remuneração (PARÁ, 1986, art. 36, § único).

De acordo com o Estatuto, será concedido pró-labore (no valor igual a um centésimo do valor do vencimento base fixado neste Estatuto para 
a referência inicial do nível em que estiver localizado o docente) ao professor do quadro permanente ou suplementar, excepcionalmente, por necessidade de serviço. A necessidade de serviço deverá ser expressamente justificada pelo Diretor da unidade Escolar em que estiver lotado o docente e devidamente autorizado pelo Secretário de Estado de Educação. Aos professores com Jornada de trabalho fixada em 20 (vinte) ou 30 (trinta) horas semanais poderão ser atribuídas horas aulas suplementares de até no máximo 09 horas semanais. Os com jornada de trabalho estipulada em 40 horas semanais, até 8 (oito) horas semanais. Enquanto o professor estiver percebendo pró-labore incidirão todas as vantagens a que fizer jus em razão de seu cargo efetivo (PARÁ, 1986, art. 37 § $1^{\circ}$ ao $5^{\circ}$ ).

A gratificação pelo exercício de função será concedida ao servidor que ocupar cargo de chefia ou outros cargos a que a lei determinar (PARÁ, 1986, art. 38).

\section{4 - Jornada de Trabalho}

De acordo com o Estatuto, a jornada de trabalho do professor nas unidades escolares pode ser fixada em regimes de 20, 30 e 40 horas semanais com atividades docentes em sala de aula. Para cada jornada de trabalho, pelo menos $20 \%$ deverá ser destinado para a realização de atividade extraclasse (planejamento, elaboração e correção de atividades, dentre outras). Segundo consta no Decreto $n^{0} 4.714 / 1987$ a jornada semanal de trabalho do pessoal docente é constituída por horas-aula e horas-atividade, sendo:

I - Jornada integral de trabalho de 40 (quarenta) horas semanais, sendo 32 (trinta e duas) horas-aula e 08 (oito) horas-atividade;

II - Jornada completa de trabalho de 30 (trinta) horas semanais, sendo 24 (vinte e quatro) horas-aula e 06 (seis) horas-atividade;

III - Jornada parcial de trabalho de 20 (vinte) horas semanais, sendo 16 (dezesseis) horas-aula e 04 (quatro) horas-atividade (PARÁ, 1987, art. 18, incisos I a III).

Contudo, esses dispositivos não vêm sendo cumprido, pois os 
professores têm alocada toda a sua jornada de trabalho em sala de aula.

Quanto à jornada de trabalho dos especialistas em educação foi fixada em 30 horas semanais (PARÁ, 1986, art. 50 a 52).

Segundo consta na Portaria $n^{\circ}$ 219/2007, expedida pela SEDUC, a lotação dos professores ocorrerá preferencialmente em uma só unidade de ensino, obedecendo à carga horária mínima de 100 (cem) horas e máxima de 200 (duzentas) horas mensais. Em casos excepcionais, a carga-horária poderá ser extrapolada em até no máximo 80 horas, mediante documento expedido pela escola que justifique a referida ação e autorizado pelo Secretário de Estado de Educação (art. $6^{\circ}$ incisos I e II).

\section{5 - Estímulo à formação}

Como estímulo à formação, o Estatuto prevê licença para o professor participar de atividade de formação, com ônus para o órgão de origem, em curso de aperfeiçoamento e especialização e de eventos (congresso, simpósio, ou promoções similares no País ou no exterior). Para isso, é condicionado que os Cursos e Eventos estejam diretamente ligados à educação ou de acordo com a conveniência do serviço público (PARÁ, 1986, art. 45 e 46). Como mencionado anteriormente, a forma de progressão vertical na carreira também se configura como um elemento de estímulo à formação, uma vez que só é obtida mediante a aquisição de uma nova habilitação.

A gratificação de titularidade se configura também como outro componente de estímulo à formação, pois a mesma é obtida em razão do aprimoramento da qualificação do servidor do magistério em cursos de: pós-graduação; atualização; aperfeiçoamento e especialização, reconhecidos pelo Conselho de Educação. Essa gratificação é calculada sobre o vencimento base, obedecendo aos seguintes percentuais:

I - 30\% (trinta por cento) para possuidores de Diploma de Doutorado;

II - 20\% (vinte por cento) para possuidores de Diploma de Mestrado;

III - $10 \%$ (dez por cento) para possuidores de curso com carga horária igual ou superior a 360 (trezentos 
e sessenta) horas;

IV-5\% (cinto por cento) para possuidores de curso com carga horária igual ou superior a 180 (cento e oitenta) horas (PARÁ, 1986, art. 33, incisos I a IV).

Para os professores que atuam no ensino médio e que ainda não concluíram o Ensino Superior, a Portaria n 219/2007 prevê forma de cumprimento da jornada de trabalho diferenciada com lotação de 04 (quatro) horas semanais, por turma, para desenvolver atividades interdisciplinares. Desta forma, os mesmos teriam tempo livre para conclusão da Educação Superior. Contudo, precisa ser previamente aprovado e autorizado pela direção da URE ou da USE, bem como pela SAEN (Secretaria Adjunta de Ensino) (art. 6º inciso V).

\section{6- Condições de trabalho}

Por condição de trabalho entendemos toda e qualquer orientação voltada para: lotação dos professores; definição da quantidade de alunos por turma; número de horas de trabalho em sala e fora dela; as férias; o recesso escolar; as licenças, às condições dos prédios escolares; utilização de materiais de ensino apropriado; dentre outras.

No Estatuto do Magistério do Estado do Pará, entretanto, encontramos apenas regulamentações relacionadas: às Férias de quarenta e cinco dias, após um ano de efetivo exercício (PARÁ, 1986, art. 47); à carga horária para atividades extraclasse (PARÁ, 1987, art. 18, incisos I a III); ao pró-labore (PARÁ, 1986, art. $37 \S \S 1^{\circ}$ e $2^{\circ}$ ) e hora suplementar (PARÁ, 1986, art. 37 §§ e $2^{\circ}$ ). Não foi encontrada regulamentação para lotação dos professores ${ }^{11}$, para a definição do número de alunos por turma ${ }^{12}$ ou que dissesse respeito

11 Para informações relacionadas a lotação ver Portaria n ${ }^{0}$ 219/2007 publicada no Diário Oficial do Estado No 31052 de 22/11/2007.

12 No que diz respeito ao número de alunos por sala a RESOLUÇÃO № 001 de 05/01/2010, determina que: Art. $\mathbf{8}^{\circ}$. Com vistas ao acolhimento do disposto no artigo 25 da Lei de Diretrizes e Bases da Educação Nacional - LDB n. 9.394/1996, o atendimento à demanda escolar nas unidades escolares do Sistema Estadual de Ensino do Pará se dará de acordo com os seguintes requisitos qualitativos mínimos:

I. no tocante à relação professor-aluno:

a) até 08 alunos por professor em classes que abriguem crianças de 0 a 1 ano; b) até 15 alunos por professor em classes que abriguem crianças de 1 a 3 anos; c) até 25 alunos por professor em classes de pré-escola e nos dois primeiros anos do Ensino Fundamental; d) até 35 alunos por professor em classes dos demais anos iniciais do Ensino Fundamental; e) até 40 alunos por professor em classes dos anos finais do Ensino Fundamental, do Ensino Médio e de Educação de Jovens e Adultos. 
às condições dos prédios escolares e existência de estagiários ${ }^{13}$.

\section{3- Dinâmica do Vencimento-Base e da Remuneração do Grupo Magistério do Quadro Permanente.}

O conjunto de tabelas, a seguir, apresenta os valores do vencimento-base dos professores pertencentes ao Quadro Permanente, segundo o nível de formação e jornada de trabalho, revelando que o vencimento dos professores com formação em nível médio foi ampliado em maiores proporções.

Tabela 1:

Evolução do Vencimento Base dos Professores do Quadro Permanente do Magistério - QPM - Gov. do Estado do Pará (Início da Carreira)

\begin{tabular}{c|c|c|c|c|c|c|c|c|c}
\hline & \multicolumn{3}{|c|}{ JORNADA 20 HS } & \multicolumn{2}{c|}{ JORNADA 30 HS } & \multicolumn{2}{c}{ JORNADA 40 HS } \\
\hline Formação & EM & LP & ESP. & EM & LP & ESP & EM & LP & ESP. \\
\hline 1996 & 367,93 & 489,28 & 489,28 & 584,74 & 733,88 & 733,88 & 735,85 & 978,29 & 978,29 \\
1997 & 359,57 & 446,29 & 446,29 & 539,36 & 669,40 & 669,40 & 719,14 & 892,33 & 892,33 \\
1998 & 372,73 & 427,04 & 427,04 & 559,10 & 640,53 & 640,53 & 745,46 & 853,84 & 853,84 \\
1999 & 359,24 & 393,42 & 393,42 & 538,86 & 590,11 & 590,11 & 718,48 & 786,64 & 786,64 \\
2000 & 357,03 & 361,69 & 361,69 & 535,54 & 542,54 & 542,54 & 714,05 & 723,38 & 723,38 \\
2001 & 385,36 & 390,41 & 390,41 & 578,05 & 585,61 & 585,61 & 770,73 & 780,74 & 780,74 \\
2002 & 392,64 & 397,28 & 397,28 & 588,96 & 595,90 & 595,90 & 785,28 & 794,47 & 794,47 \\
2003 & 353,14 & 356,06 & 356,06 & 529,71 & 534,09 & 534,09 & 706,28 & 712,12 & 712,12 \\
2004 & 362,84 & 365,61 & 365,61 & 544,25 & 548,41 & 548,41 & 725,67 & 731,21 & 731,21 \\
2005 & 375,14 & 375,14 & 375,14 & 562,71 & 562,71 & 562,71 & 750,28 & 750,28 & 750,28 \\
2006 & 441,72 & 467,96 & 467,96 & 662,59 & 701,94 & 701,94 & 883,45 & 935,82 & 935,82 \\
2007 & 462,98 & 490,49 & 490,49 & 694,47 & 735,73 & 735,73 & 925,97 & 980,90 & 980,90 \\
2008 & 464,12 & 475,73 & 475,73 & 696,17 & 713,60 & 713,60 & 928,23 & 951,38 & 951,38 \\
2009 & 484,14 & 484,16 & 484,16 & 726,21 & 726,24 & 726,24 & 968,28 & 968,28 & 968,28 \\
2010 & 517,59 & 519,11 & 519,11 & 776,38 & 778,67 & 778,67 & $1.035,17$ & $1.038,21$ & $1.038,21$ \\
$\%$ Cres. & 40,68 & 6,10 & 6,10 & 32,77 & 6,10 & 6,10 & 40,68 & 6,12 & 6,12 \\
\hline
\end{tabular}

Fonte: Tabelas Salariais - Diário Oficial e Decretos. Corrigido pelo IGPD-I a preço de maio/2010

Os dados da tabela 1 mostram que, de 1996 a 2010, o vencimentobase dos professores, com formação em nível médio, cresceu em 40,7\% e dos professores com formação em nível superior, em 6,1\%. Essa política salarial que priorizou o salário dos professores de nível médio

13 Para informações mais detalhadas acerca da regulamentação do Estágio ver RESOLUÇÃO Nº 001 de 05/01/2010, artigos 124 a 135. 
contribuiu para redução significativa da diferença salarial entre esses professores com os de nível superior. Enquanto, em 1996, a diferença salarial correspondia a 33,0\%, em 2010, está sendo de 0,3\%. Esse resultado expressa tendência de igualar o vencimento-base numa política que prioriza o professor com formação em nível médio.

No que concerne à remuneração dos professores, as tabelas 2 e 3 mostram que embora o percentual de aumento em relações aos docentes com formação em nível superior tenha sido maior, permanece inferior ao praticado na remuneração dos professores com formação em nível médio.

Tabela 2:

Participação Percentual do Vencimento Base e Gratificações na Remuneração dos Professores do Quadro Permanente do Magistério - QPM - Gov. do Estado do Pará - Formação Nível Médio (Início da Carreira)

\begin{tabular}{|c|c|c|c|c|c|c|c|c|c|}
\hline & \multicolumn{3}{|c|}{ JORNADA $20 \mathrm{HS}$} & \multicolumn{3}{|c|}{ JORNADA $30 \mathrm{HS}$} & \multicolumn{3}{|c|}{ JORNADA $40 \mathrm{HS}$} \\
\hline & REM & $\begin{array}{c}\% \\
\text { VENC. }\end{array}$ & $\begin{array}{c}\% \\
\text { GRAT. }\end{array}$ & REM & $\begin{array}{c}\% \\
\text { VENC. }\end{array}$ & $\begin{array}{c}\% \\
\text { GRAT. }\end{array}$ & REM & $\begin{array}{c}\% \\
\text { VENC. }\end{array}$ & $\begin{array}{c}\% \\
\text { GRAT. }\end{array}$ \\
\hline 1996 & 501,86 & 73,31 & 26,69 & 718,67 & 81,36 & 18,64 & 869,78 & 84,60 & 15,40 \\
\hline 1997 & 490,45 & 73,31 & 26,69 & 670,24 & 80,47 & 19,53 & 850,02 & 84,60 & 15,40 \\
\hline 1998 & 542,81 & 68,67 & 31,33 & 729,18 & 76,68 & 23,32 & 915,55 & 81,42 & 18,58 \\
\hline 1999 & 521,69 & 68,86 & 31,14 & 701,32 & 76,84 & 23,16 & 880,94 & 81,56 & 18,44 \\
\hline 2000 & 514,98 & 69,33 & 30,67 & 693,49 & 77,22 & 22,78 & 872,01 & 81,89 & 18,11 \\
\hline 2001 & 551,00 & 69,94 & 30,06 & 743,68 & 77,73 & 22,27 & 936,37 & 82,31 & 17,69 \\
\hline 2002 & 558,85 & 70,26 & 29,74 & 755,17 & 77,99 & 22,01 & 951,49 & 82,53 & 17,47 \\
\hline 2003 & 503,58 & 70,13 & 29,87 & 680,15 & 77,88 & 22,12 & 856,72 & 82,44 & 17,56 \\
\hline 2004 & 522,61 & 69,43 & 30,57 & 704,03 & 77,31 & 22,69 & 885,44 & 81,96 & 18,04 \\
\hline 2005 & 549,21 & 68,31 & 31,69 & 736,78 & 76,37 & 23,63 & 924,35 & 81,17 & 18,83 \\
\hline 2006 & 640,37 & 68,98 & 31,02 & 861,24 & 76,93 & 23,07 & $1.082,10$ & 81,64 & 18,36 \\
\hline 2007 & 667,65 & 69,35 & 30,65 & 899,14 & 77,24 & 22,76 & $1.130,63$ & 81,90 & 18,10 \\
\hline 2008 & 665,97 & 69,69 & 30,31 & 898,02 & 77,52 & 22,48 & $1.130,08$ & 82,14 & 17,86 \\
\hline 2009 & 691,60 & 70,00 & 30,00 & 933,67 & 77,78 & 22,22 & $1.175,74$ & 82,35 & 17,65 \\
\hline 2010 & 736,35 & 70,29 & 29,71 & 995,14 & 78,02 & 21,98 & $1.253,94$ & 82,55 & 15,40 \\
\hline \%Cres. & 46,72 & & & 38,46 & & & 44,17 & & \\
\hline
\end{tabular}

Fonte: Tabelas Salariais - Diário Oficial Corrigido pelo IGPD-I a preço de maio/2010.

Os dados da tabela 2 mostram ainda que o peso das gratificações na remuneração dos professores com formação em nível médio variou de 29,7 a 31,7\%, no decorrer da série histórica (1996/2010). Considerando-se os anos 
extremos da série verifica-se o peso permanece praticamente o mesmo.

Observa-se ainda que o peso das gratificações na remuneração tende a diminuir a medida que aumenta a jornada de trabalho do Professor.

No entanto, o peso é alterado quando se trata dos professores com formação em nível superior, conforme os dados da tabela 3.

Tabela 3:

Participação Percentual do Vencimento Base e Gratificações na Remuneração dos Professores do Quadro Permanente do Magistério QPM - Gov. do Estado do Pará - Formação Nível Superior (Início da Carreira)

\begin{tabular}{c|c|c|c|c|c|c|c|c|c}
\hline & \multicolumn{3}{|c|}{ JORNADA 20 HS } & \multicolumn{2}{c|}{ JORNADA 30 HS } & \multicolumn{3}{c}{ JORNADA 40 HS } \\
\hline & REM & $\begin{array}{c}\% \\
\text { VENC. }\end{array}$ & $\begin{array}{c}\text { \% } \\
\text { GRAT. }\end{array}$ & REM & $\begin{array}{c}\text { \% } \\
\text { VENC. }\end{array}$ & $\begin{array}{c}\% \\
\text { GRAT. }\end{array}$ & REM & $\begin{array}{c}\% \\
\text { VENC. }\end{array}$ & $\begin{array}{c}\% \\
\text { GRAT. }\end{array}$ \\
\hline 1996 & $1.075,36$ & 45,50 & 52,13 & $1.320,00$ & 55,60 & 44,40 & $1.564,64$ & 62,54 & 37,46 \\
1997 & $1.017,52$ & 43,86 & 53,78 & $1.240,67$ & 53,96 & 46,04 & $1.463,81$ & 60,98 & 39,02 \\
1998 & $1.008,04$ & 42,36 & 55,29 & $1.221,56$ & 52,44 & 47,56 & $1.435,08$ & 59,51 & 40,49 \\
1999 & 928,69 & 42,36 & 55,29 & $1.125,41$ & 52,44 & 47,56 & $1.322,12$ & 59,51 & 40,49 \\
2000 & 852,66 & 42,42 & 55,24 & $1.033,51$ & 52,49 & 47,51 & $1.214,35$ & 59,57 & 40,43 \\
2001 & 915,49 & 42,65 & 55,01 & $1.110,69$ & 52,73 & 47,27 & $1.305,90$ & 59,79 & 40,21 \\
2002 & 929,06 & 42,76 & 54,89 & $1.127,69$ & 52,84 & 47,16 & $1.326,34$ & 59,91 & 40,09 \\
2003 & 862,44 & 41,29 & 56,39 & $1.040,47$ & 51,33 & 48,67 & $1.218,50$ & 58,44 & 41,56 \\
2004 & 889,07 & 41,12 & 56,55 & $1.071,87$ & 51,16 & 48,84 & $1.254,68$ & 58,28 & 41,72 \\
2005 & 921,35 & 40,72 & 56,96 & $1.108,92$ & 50,74 & 49,26 & $1.296,49$ & 57,87 & 42,13 \\
2006 & $1.140,38$ & 41,04 & 56,64 & $1.374,36$ & 51,07 & 48,93 & $1.608,34$ & 58,19 & 41,81 \\
2007 & $1.191,72$ & 41,16 & 56,52 & $1.436,96$ & 51,20 & 48,80 & $1.682,21$ & 58,31 & 41,69 \\
2008 & $1.153,75$ & 41,23 & 56,44 & $1.391,61$ & 51,28 & 48,72 & $1.629,48$ & 58,39 & 41,61 \\
2009 & $1.171,91$ & 41,31 & 56,36 & $1.413,99$ & 51,36 & 48,64 & $1.656,07$ & 58,47 & 41,53 \\
2010 & $1.253,39$ & 43,66 & 53,98 & $1.448,59$ & 53,75 & 46,25 & $1.708,14$ & 60,78 & 39,22 \\
$\%$ Cres. & 26,60 & - & - & 9,74 & - & - & 9,17 & - & - \\
\hline
\end{tabular}

Fonte: Tabelas Salariais - Diário Oficial e Decretos. Corrigido pelo IGPD-I a preço de maio/2010

Os dados mostram que o peso das gratificações na remuneração dos professores licenciados plenos correspondeu a percentuais um pouco acima de 50\%, revelando sua importância. Observa-se ainda a tendência de redução do peso a medida que a jornada de trabalho é ampliada. 


\section{4- Considerações finais}

As análises empreendidas por diversos autores acerca dos Estatutos, da Carreira docente e suas diretrizes (DUTRA JÚNIOR, 2000; MORDUCHOWICZ, 2003; ABREU, 2008; FREITAS, 2009, ROCHA, 2009; NORONHA, 2009, CNTE, 2009; GATTI e BARRETO, 2009) revelam que, apesar de os Planos e/ou Estatutos se organizarem numa lógica estrutural individualizada para os profissionais do magistério, são instrumentos coletivos capazes de promover tanto a valorização profissional quanto a efetividade do direito à educação de qualidade para todos. Embora os estudos revelem que a carreira por si só não assegura melhoria da qualidade da educação, possibilita: definir padrões de formação inicial e continuada; produzir condições de trabalho em conformidade com as necessidades postas para realização do trabalho educativo; acesso e progressão (vertical e horizontal) na carreira; aumento de remuneração; definição de carga horária; aperfeiçoamento profissional; hora-atividade para estudo e planejamento, etc. A efetivação desses fatores é fundamental para a concretização do princípio constitucional da "Valorização Docente".

Na perspectiva de reforçar a relevância deste instrumento para a valorização do professor e para a melhoria da qualidade do ensino público, ao longo dos últimos anos, foi aprovado um conjunto de leis (Regime Jurídico Único dos Servidores do Estado de 1994 - Lei nº 5.810 -, aprovada a LDB - Lei $\mathrm{n}^{\circ}$ 9.394/1996 - e, principalmente, o FUNDEF - Lei n $9424 / 1996$-, o FUNDEB - Lei n ${ }^{\circ} 11.494 / 2007$ - , a Lei do Piso Nacional Lei $n^{\circ} 11.738 / 2008$ - e a Resolução CNE/CEB No 2 de 28 de maio de 2009) contendo novas regulamentações que implicavam diretamente sobre o Estatuto do Magistério do Pará, instituído há mais de vinte anos pela Lei $n^{0} 5.351$ de 21/11/1986

Dada a antiguidade do Estatuto, urge necessária sua adequação às novas orientações legais e conceitos (como resultado das reivindicações e da luta dos trabalhadores em educação), estabelecidos desde a

14 A lei 5.692/71 estabelecia que, em cada sistema de ensino, deveria haver um Estatuto que estruturasse a carreira do Magistério de $1^{\circ}$ e $2^{\circ}$ graus com acessos graduais e sucessivos (Brasil, 1971, art. 36). 
Constituição Federal de 1988 e das legislações específicas da educação, como: a lei do Piso; do FUNDEB, e das novas Diretrizes para Carreira.

Nessa perspectiva, a análise empreendida acerca do Estatuto do Magistério da Rede Estadual de Ensino do Pará, permitiu-nos constatar que: - No que diz respeito ao Ingresso inicial na Carreira e tipo de profissional atraído, embora o Estatuto tenha previsto a realização de concurso público de provas ou de provas e títulos - o que configuraria avanço para época - restringiu-se apenas a "primeira investidura no cargo", abrindo-se a possibilidade de ingresso na carreira por meio da "ascensão" - mecanismo de burla ao concurso público vetado constitucionalmente (CF/1988, art. 37, inciso II). Além disso, permitiuse o ingresso de professores leigos para compor o quadro suplementar do magistério. Este tipo de abertura, aliado, dentre outros fatores, a ausência de uma política de formação ao longo dos anos, contribuíram para a presença expressiva desse tipo de profissional na rede pública estadual de ensino. De acordo com dados divulgados pelo MEC/INEP, apenas $10 \%$ das funções docentes exercidas na educação básica, no Pará, são desempenhadas por professores com formação inicial adequada. Os demais carecem de formação inicial, em nível de graduação ou, apesar de possuírem graduação, atuam em áreas diferentes de sua formação inicial $^{15}$ (MEC/INEP - EDUCACENSO, 2007).

- No que refere ao valor do vencimento e remuneração do professor, é determinado de acordo com o nível de formação e não na etapa de ensino de atuação. Esses fatores, aliado a existência das gratificações (magistério, por tempo de serviço e de titularidade), pelo menos em tese, configuramse como elementos de estímulo a permanência do professor na carreira e em sala de aula, independente do nível/etapa (Educação Infantil, Ensino Fundamental ou Médio) de ensino em que estivesse lotado. Contudo, o mesmo precisaria ser reformulado (ou aprovado Lei Complementar) no sentido de adaptar os critérios estabelecidos para a composição da remuneração dos profissionais do magistério aos preceitos da Lei $n^{\circ}$

15 Em função destes números preocupantes, o Estado do Pará desde 2009 vem desenvolvendo ações previstas no Plano Estadual de Educação (PEE). O Plano de Formação Docente do Estado do Pará (PARFOR/PA) materializa o planejamento de uma dessas ações: a formação inicial e continuada de professores da educação básica de todo o Estado. 
11.738/2008, que estabelece o Piso Salarial Profissional Nacional, ao art. 22 da Lei n ${ }^{\circ}$ 11.494/2007, que dispõe sobre a parcela da verba do Fundo de Manutenção e Desenvolvimento da Educação Básica e Valorização do Magistério (FUNDEB), destinada ao pagamento dos profissionais do magistério (Resolução CNE/CEB N 2/05/2009, art. $3^{\circ}$ ).

- Embora o Estatuto possibilite a progressão horizontal (valorizando o tempo de serviço prestado como componente evolutivo) e vertical (estimulando a formação e capacitação) do professor na carreira inclusive com o direito a liberação de suas funções laborais (com ônus para o Estado) - para participar em curso de formação para a obtenção deste último, a mesma não vem sendo cumprida pelo Estado.

- A organização e lutas empreendidas pela categoria dos professores, por meio do SINTEPP, têm sido fundamentais na configuração da carreira e na sua efetivação.

A carreira do magistério dos profissionais da rede estadual de ensino do Pará, estruturada pelo Estatuto, embora contemple alguns elementos indicadores de valorização docente (progressão e hora atividade), os mesmos não são cumpridos. Além disso, os percentuais de acréscimos salariais propostos com as progressões e obtenção de novas titulações não são suficientes para a estimular a formação, atrair e manter os profissionais melhor qualificados no quadro de pessoal da SEDUC.

A incorporação de importantes demandas da categoria docente no âmbito da legislação nacional, aprovada nos últimos vinte anos, embora inseridas no corpo da legislação estadual que trata da carreira (Estatuto e PCCR), precisa refletir e resgatar a valorização social do profissional do magistério, com a garantia de progressão e percentual de aumentos estimuladores para permanência na carreira com uma remuneração condigna, capaz de assegurar para si e seus familiares a manutenção de um bom nível de vida e permitir a continuidade de sua formação (UNESCO, 1966). 


\section{Referências}

ABREU, D. C. de. Carreira e Perfil do Profissional do Magistério na Rede Municipal de Ensino de Curitiba: História e Impacto da Politica Brasileira de Valorização do Magistério. Dissertação de Mestrado, Universidade Federal do Paraná, Curitiba, 2008.

BARBOSA, Andreza. Os salários dos professores brasileiros: implicações para o trabalho docente. (208 f.) Tese (Doutorado em Educação Escolar), Faculdade de Ciências e Letras - Universidade Estadual Paulista - UNESP/Araraquara, São Paulo, 2011.

BRASIL, Constituição Federal de 1988 (atualizada até a EC 19/98). $2^{a}$ ed. São Paulo: Oliveira Mendes, 1998.

BRASIL, Lei 9.424, de 24/12/1996 (dispõe sobre o Fundo de Manutenção e Desenvolvimento do Ensino Fundamental e de Valorização do Magistério).

BRASIL. Emenda Constitucional $n^{\circ}$ 14, de 12/09/96.

BRASIL, Lei 9.394, de 20/12/1996 (dispõe sobre as Diretrizes e Bases da Educação Nacional). . Emenda Constitucional no 53, de 19/12/06.

Lei $n^{\circ} 11.494$, de 20/07/07.

CNTE. Diretrizes para a carreira e remuneração. - Brasília: Confederação Nacional dos Trabalhadores em Educação (Cadernos de Educação n. 21, 2 ed.), 161 p. 2009.

DUTRA JÚNIOR, Adhemar.; ABREU, Mariza; MARTINS, Ricardo; BALZANO, Sonia. Plano de Carreira e Remuneração do Magistério 
Público: LDB, FUNDEF, Diretrizes Nacionais e nova concepção de carreira. Brasília: FUNDESCOLA/ MEC, 2000.

FREITAS, Maria. Helena. L da C. Apreciação sobre as Diretrizes de Carreira aprovadas pelo CNE IN: NORONHA, M. I. A. Diretrizes Nacionais para os novos Planos de Carreira e de Remuneração para o Magistério dos Estados, do Distrito Federal e dos Municípios. Brasília: MEC/CNE, 28/05/2009.

GEMAQUE, Rosana Maria. O Financiamento da Educação. O FUNDEF no Estado do Pará: Feitos e Fetiches. São Paulo - SP, 2004, 370p. (Tese de Doutorado, USP/FEUSP).

MORDUCHOWICZ, Alejandro. Carreiras, incentivos e estruturas salariais docentes. Documentos PREAL, Washington, n. 23, p. 1-60, jun., 2003. Disponível em: http:/ / www.oei.es/docentes/articulos/ carreras_incentivos_estructuras_salariales_docentes_morduchowicz_ portugues.pdf . Acesso em: 17/05/2011.

NORONHA, Maria Izabel A. Diretrizes Nacionais para os novos Planos de Carreira e de Remuneração para o Magistério dos Estados, do Distrito Federal e dos Municípios. Brasília: MEC/CNE, 28/05/2009.

PARÁ, Assembléia Legislativa do Estado do. LEI N ${ }^{0}$ 5.351, DE 21 DE NOVEMBRO DE 1986. Dispõe sobre o Estatuto do Magistério Público Estadual do Pará.

PARÁ, Assembléia Legislativa do Estado do. DECRETO N 4.714 DE 09 DE FEVEREIRO DE 1987. Regulamenta o Estatuto do Magistério Público Estadual do Pará.

ROCHA, Maria da Consolação. Políticas de Valorização do Magistério: remuneração, plano de carreira, condições de trabalho - uma análise da experiência de Belo Horizonte. (Tese de Doutorado). São Paulo: FEUSP, 2009. 


\title{
The configuration of the magisterium public career of Pará from the Statute of Magisterium
}

\begin{abstract}
:
This article aims at presenting the main aspects os the Statute os the Public Magisterium of Pará (State Law 5.351/1986), in order to understand the career of teaching the publico $f$ the State of Pará. For this, the following aspects were analyzed: forms of entry, amplitude and movement in the career. From setting career, Wonders whether the same features: attractiveness, progression and incentives for formation. The text is organized to form a cover aspects that allow discuss about the historical context, showing the construction of career; issues of conceptual order on Status anda Career Planning and Job anda Remuneration. Concluded that, from a legal standpoint, a career, set by statute, Complementary Laws anda Ordinances, ensures the rights of the public teaching professionals that puts them inf position isonomic with other public servants, such as Holiday allowances; professional qualification; progression; additional. Althought it contains elements os attractiveness of staying the teacher in the classroom through bonuses, in practice, its effectiveness has occurred only partially. Some aspects are not being met by the last three governmets, such as vertical progression and time activity. The partial maintenance of the rights assured by the Statute hás been the product of historical struggles category.
\end{abstract}

Keywords: Statute of the Magisterium of Pará; Career anda Teacher's Remuneration.

Recebido: 18/01/12

Aprovado: 26/06/12 